\title{
Description of a new species of Music frogs (Anura, Ranidae, Nidirana) from Mt Dayao, southern China
}

\author{
Zhi-Tong Lyu', Yun-Ming $\mathrm{Mo}^{2}$, Han Wan', Yu-Long Li', \\ Hong Pang', Ying-Yong Wang'
}

I State Key Laboratory of Biocontrol/ The Museum of Biology, School of Life Sciences, Sun Yat-sen University, Guangzhou 510275, China 2 Natural History Museum of Guangxi, Nanning 530012, China

Corresponding author: Ying-Yong Wang (wangyy@mail.sysu.edu.cn); Hong Pang (lsshpang@mail.sysu.edu.cn)

Academic editor: A. Obler | Received 7 March 2019 | Accepted 28 May 2019 | Published 1 July 2019

http://zoobank.org/8AA495F6-CCC3-4E00-B37B-BAF5A598A2ED

Citation: Lyu Z-T, Mo Y-M, Wan H, Li Y-L, Pang H, Wang Y-Y (2019) Description of a new species of Music frogs (Anura, Ranidae, Nidirana) from Mt Dayao, southern China. ZooKeys 858: 109-126. https://doi.org/10.3897/ zookeys.858.34363

\begin{abstract}
A new species of Music frogs, Nidirana yaoica sp. nov. is described based on a series of adult male specimens collected from Mt Dayao, Guangxi, southern China, providing valuable new information on the phylogeny, bioacoustics, and biogeography of related species within the genus Nidirana. The new species forms the sister taxon to $N$. daunchina from western China and together the sister taxon to $N$. chapaensis from northern Vietnam. Nidirana yaoica sp. nov. can be distinguished from all known congeners by a significant genetic divergence in the mitochondrial $16 \mathrm{~S}$ and CO1 genes, the advertisement call containing 1-3 rapidly repeated regular notes, and the combination of morphological characteristics including a medium-sized body with SVL 40.4-45.9 mm in adult males; lateroventral grooves on every digit, not meeting at the tip of disk; tibio-tarsal articulation reaching the nostril; the presence of a pair of subgular vocal sacs in males; and one single developed nuptial pad on dorsal surface of first finger in males.
\end{abstract}

\section{Keywords}

bioacoustic, Guangxi, mitochondrial DNA, morphology, Nidirana yaoica sp. nov.

Copyright Zhi-Tong Lyu et al. This is an open access article distributed under the terms of the Creative Commons Attribution License (CC BY 4.0), which permits unrestricted use, distribution, and reproduction in any medium, provided the original author and source are credited. 


\section{Introduction}

The taxonomic treatment of the Music frog genus Nidirana Dubois, 1992 was controversial for a long time (Dubois 1987, 1992; Chen et al. 2005; Frost et al. 2006; Fei et al. 2009, 2010; Chuaynkern et al. 2010). The recent contribution to the phylogeny of genus Nidirana reconsidered it as a distinct genus, on the basis of comprehensive evidence of morphology, molecular phylogeny, bioacoustics, and biogeography (Lyu et al. 2017). Eight Music frog species were recognized from subtropical eastern and southeastern Asia (Lyu et al. 2017; Frost 2019): N. okinavana (Boettger, 1895) from Yaeyama of southern Ryukyu, and eastern Taiwan; N. adenopleura (Boulenger, 1909) from Taiwan and southeastern mainland China; N. nankunensis Lyu, Zeng, Wang, Lin, Liu \& Wang, 2017 from Mt Nankun of Guangdong and N. hainanensis (Fei, Ye, $\&$ Jiang, 2007) from Mt Diaoluo of Hainan, both in southern China; $N$. daunchina (Chang, 1933) from western China; $N$. pleuraden (Boulenger, 1904) from southwestern China; and $N$. chapaensis (Bourret, 1937) and N. lini (Chou, 1999) from the northeastern Indochinese peninsula.

During our herpetological field surveys in Mt Dayao (MDY), Guangxi, south China, we collected a series of specimens of a small-sized frog that could be assigned to the genus Nidirana by possessing large suprabrachial gland in breeding males. Further detailed comprehensive analyses of molecules, bioacoustics, and morphology indicated that this frog was distinctive from all known congeners of Nidirana. Therefore, we propose it as a new species based on this study.

\section{Materials and methods}

\section{Taxon sampling}

Eight muscular samples of the unnamed species from MDY were used for molecular analysis. All samples were attained from euthanasia specimens and then preserved in $95 \%$ ethanol and stored at $-40{ }^{\circ} \mathrm{C}$. In addition, 36 sequences from all known Nidirana species and two sequences from the out-group Babina were obtained from GenBank and incorporated into our dataset. Detail information of these materials is shown in Table 1 and Fig. 1.

\section{DNA Extraction, PCR amplification, and sequencing}

Genomic DNA were extracted from muscle tissue samples, using DNA extraction kit from Tiangen Biotech (Beijing) Co., Ltd. Two mitochondrion genes, namely partial $16 \mathrm{~S}$ ribosomal RNA gene (16S) and partial cytochrome $\mathrm{C}$ oxidase 1 gene (CO1), were amplified. Primers used for $16 S$ were L3975 (5'-CGCCTGTTTACCAAAAACAT-3') and H4551 (5'-CCGGTCTGAACTCAGATCACGT-3'), and L2A (5'-CCAAACGAGC- 
Table I. Localities, voucher information, and GenBank numbers for all samples used in this study.

\begin{tabular}{|c|c|c|c|c|c|}
\hline ID & Species & Localities $(*=$ type localities) & Voucher & $16 S$ & $\mathrm{CO1}$ \\
\hline 1 & Nidirana yaoica sp. nov. & China: Guangxi: Mt Dayao * & SYS a007009 & MK882271 & MK895036 \\
\hline 2 & Nidirana yaoica sp. nov. & China: Guangxi: Mt Dayao * & SYS a007011 & MK882272 & MK895037 \\
\hline 3 & Nidirana yaoica sp. nov. & China: Guangxi: Mt Dayao * & SYS a007012 & MK882273 & MK895038 \\
\hline 4 & Nidirana yaoica sp. nov. & China: Guangxi: Mt Dayao * & SYS a007013 & MK882274 & MK895039 \\
\hline 5 & Nidirana yaoica sp. nov. & China: Guangxi: Mt Dayao * & SYS a007014/CIB 110013 & MK882275 & MK895040 \\
\hline 6 & Nidirana yaoica sp. nov. & China: Guangxi: Mt Dayao * & SYS a007020 & MK882276 & MK895041 \\
\hline 7 & Nidirana yaoica sp. nov. & China: Guangxi: Mt Dayao * & SYS a007021 & MK882277 & MK895042 \\
\hline 8 & Nidirana yaoica sp. nov. & China: Guangxi: Mt Dayao * & SYS a007022 & MK882278 & MK895043 \\
\hline 9 & Nidirana adenopleura & China: Zhejiang: Jingning & SYS a002725 & MF807827 & MF807866 \\
\hline 10 & Nidirana adenopleura & China: Fujian: Nanping & SYS a005911 & MF807844 & MF807883 \\
\hline 11 & Nidirana adenopleura & China: Fujian: Mt Wuyi & SYS a005940 & MF807851 & MF807890 \\
\hline 12 & Nidirana adenopleura & China: Fujian: Mt Wuyi & SYS a005941 & MF807852 & MF807891 \\
\hline 13 & Nidirana adenopleura & China: Fujian: Mt Wuyi & XM2827 & KF771281 & l \\
\hline 14 & Nidirana adenopleura & China: Taiwan: New Taipei & UMMZ 189963 & DQ283117 & l \\
\hline 15 & Nidirana adenopleura & Not given & NMNS 2384 & AF458118 & I \\
\hline 16 & Nidirana adenopleura & Not given & A-A-WZ001 & NC018771 & NC018771 \\
\hline 17 & Nidirana chapaensis & Vietnam: Lao Cai: Sapa * & ROM 28070 & AF206460 & l \\
\hline 18 & Nidirana chapaensis & Vietnam: Lao Cai: Sapa * & 1999.5871 & KR827710 & I \\
\hline 19 & Nidirana chapaensis & Vietnam: Lao Cai: Sapa* & T2483/2000.4850 & KR827711 & KR087625 \\
\hline 20 & Nidirana chapaensis & Vietnam: Gia Lai & AMSR176027 & KU840598 & I \\
\hline 21 & Nidirana daunchina & China: Sichuan: Mt Emei * & 0609 & KU840597 & I \\
\hline 22 & Nidirana daunchina & China: Sichuan: Mt Emei * & CIB-WU37990 & DQ359988 & l \\
\hline 23 & Nidirana daunchina & China: Sichuan: Mt Emei * & HNNU 20060103 & KF185065 & I \\
\hline 24 & Nidirana daunchina & China: Sichuan: Mt Emei * & SYS a004594 & MF807822 & MF807861 \\
\hline 25 & Nidirana daunchina & China: Sichuan: Mt Emei * & SYS a004595 & MF807823 & MF807862 \\
\hline 26 & Nidirana daunchina & China: Sichuan: Hejiang & SYS a004930 & MF807824 & MF807863 \\
\hline 27 & Nidirana daunchina & China: Sichuan: Hejiang & SYS a004931 & MF807825 & MF807864 \\
\hline 28 & Nidirana daunchina & China: Sichuan: Hejiang & SYS a004932 & MF807826 & MF807865 \\
\hline 29 & Nidirana daunchina & Not given & Not given & I & HQ395353 \\
\hline 30 & Nidirana hainanensis & China: Hainan: Mt Diaoluo * & SYS a003741 & MF807821 & MF807860 \\
\hline 31 & Nidirana hainanensis & China: Hainan & Not given & KU840596 & I \\
\hline 32 & Nidirana lini & China: Yunnan: Jiangcheng * & SYS a003967 & MF807818 & MF807857 \\
\hline 33 & Nidirana lini & China: Yunnan: Jiangcheng * & SYS a003968 & MF807819 & MF807858 \\
\hline 34 & Nidirana lini & China: Yunnan: Jiangcheng * & SYS a003969 & MF807820 & MF807859 \\
\hline 35 & Nidirana lini & China: Yunnan: Lyuchun & HNNULC001 & KF185066 & I \\
\hline 36 & Nidirana lini & Laos: Xieng Khouang & FMNH256531 & KR264073 & l \\
\hline 37 & Nidirana lini & Laos: Xieng Khouang & FMNH256532 & KR264074 & l \\
\hline 38 & Nidirana lini & Not given & Not given & 1 & HQ395352 \\
\hline 39 & Nidirana nankunensis & China: Guangdong: Mt Nankun * & SYS a005717 & MF807838 & MF807877 \\
\hline 40 & Nidirana nankunensis & China: Guangdong: Mt Nankun * & SYS a005718 & MF807839 & MF807878 \\
\hline 41 & Nidirana nankunensis & China: Guangdong: Mt Nankun * & SYS a005719 & MF807840 & MF807879 \\
\hline 42 & Nidirana okinavana & Japan: Okinawa: Iriomote Island * & Not given & NC022872 & $\mathrm{NC} 022872$ \\
\hline 43 & Nidirana pleuraden & China: Yunnan: Mt Gaoligong & SYS a003775 & MF807816 & MF807855 \\
\hline 44 & Nidirana pleuraden & China: Yunnan: Mt Gaoligong & SYS a003776 & MF807817 & MF807856 \\
\hline 45 & Babina holsti & Japan: Okinawa * & Not given & NC022870 & $\mathrm{NC} 022870$ \\
\hline 46 & Babina subaspera & Japan: Kagoshima: Amami Island * & Not given & $\mathrm{NC} 022871$ & NC022871 \\
\hline
\end{tabular}




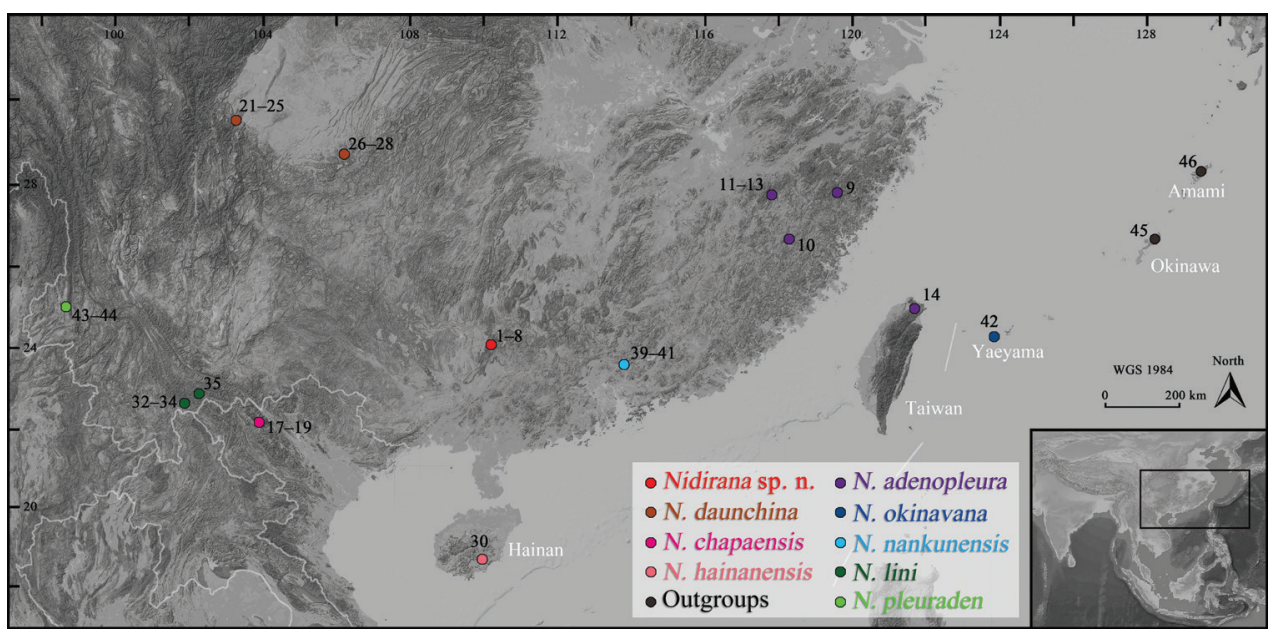

Figure I. Localities of the samples used in this study. The numbers correspond to the ID numbers in Table 1.

CTAGTGATAGCTGGTT-3') and H10 (5'-TGATTACGCTACCTTTGCACGGT-3'), and for CO1 were Chmf4 (5'-TYTCWACWAAYCAYAAAGAYATCGG-3') and Chmr4 (5'-ACYTCRGGRTGRCCRAARAATCA-3'), and dgLCO (5'-GGTCAACAAATCATAAAGAYATYGG-3') and dgHCO (5'-AAACTTCAGGGTGACCAAARAAYCA-3'), following Lyu et al. (2019). PCR amplifications were processed with the cycling conditions that initial denaturing step at $95^{\circ} \mathrm{C}$ for $4 \mathrm{~min}, 35$ cycles of denaturing at $94^{\circ} \mathrm{C}$ for $40 \mathrm{~s}$, annealing at $53^{\circ} \mathrm{C}$ (for $16 \mathrm{~S}$ ) $/ 48^{\circ} \mathrm{C}$ (for CO1) for $40 \mathrm{~s}$ and extending at $72{ }^{\circ} \mathrm{C}$ for $60 \mathrm{~s}$, and a final extending step at $72{ }^{\circ} \mathrm{C}$ for $10 \mathrm{~min}$. PCR products were purified with spin columns and then sequenced with both forward and reverse primers using BigDye Terminator Cycle Sequencing Kit per the guidelines, on an ABI Prism 3730 automated DNA sequencer by Shanghai Majorbio Bio-pharm Technology Co, Ltd. All sequences were deposited in GenBank (Table 1).

\section{Phylogenetic analyses}

DNA sequences were aligned by the Clustal W algorithm with default parameters (Thompson et al. 1997) and trimmed with the gaps partially deleted in MEGA 6 (Tamura et al. 2013). Two gene segments, 1041 base pairs (bp) of $16 \mathrm{~S}$ and $573 \mathrm{bp}$ of $\mathrm{CO} 1$, were concatenated seriatim into a 1614 -bp sequence, and further divided into four partitions by codons. The partitions were tested in jmodeltest v2.1.2 with Akaike and Bayesian information criteria, all resulting the best-fitting nucleotide substitution models of GTR $+\mathrm{I}+\mathrm{G}$. Sequenced data was analyzed using Bayesian inference (BI) in MrBayes 3.2.4 (Ronquist et al. 2012), and maximum likelihood (ML) in RaxmlGUI 1.3 (Silvestro and Michalak 2012). Two independent runs were conducted in a BI analysis, each of which was performed for 10,000,000 generations and sampled every 1000 generations with the first $25 \%$ samples were discarded as burn-in, resulting a 
potential scale reduction factor (PSRF) of $<0.005$. In ML analysis, the bootstrap consensus tree inferred from 1000 replicates was used to represent the evolutionary history of the taxa analyzed.

\section{Bioacoustic analysis}

Advertisement calls of the specimen SYS a007009 from MDY were recorded in the field at the air temperature of $18^{\circ} \mathrm{C}$ using a SONY PCM D100 digital sound recorder. The sound files in wave format were sampled at $44.1 \mathrm{kHz}$ with 24 bits in depth. Praat 6.0.27 (Boersma 2001) was used to obtain the oscillogram, sonogram, and power spectrum (window length $=0.005 \mathrm{~s}$ ). Raven pro 1.5 (Cornell Lab of Ornithology, 2003-2014) was used to quantify the acoustic properties (window size $=256$ points, fast Fourier transform, Hanning window with no overlap). The following measurements were taken for each call: call duration (the time between onset of the first note and offset of the last note in a call) and call PF (peak frequency; the frequency at which max power occurs within the call); the following measurements were taken for each note: note duration (the time between onset and offset of a note), note rise time (the time between onset and max amplitude of a note), note interval (the time between adjacent notes in a call), note PF and note IQR-BW (inter-quartile range bandwidth; the difference between the first and third quartile frequencies within a note). Mean and standard deviation (SD) were calculated in R 3.3.2 (R Core Team 2016).

\section{Morphology}

Comparison characters of all known congeners were obtained from the literature (Boettger 1895; Boulenger 1904, 1909; Schmidt 1925; Chang and Hsu 1932; Bourret 1937; Kuramoto 1985; Chou 1999; Fei et al. 2007, 2009; Matsui 2007; Chuaynkern et al. 2010; Lyu et al. 2017) and 55 examined museum specimens of six species which are listed in the Appendix 1. All specimens were fixed in 10\% buffered formalin and later transferred to $70 \%$ ethanol, and deposited in the Museum of Biology, Sun Yatsen University (SYS), Natural History Museum of Guangxi (NHMG), and Chengdu Institute of Biology, Chinese Academy of Sciences (CIB), China.

Morphological descriptions follow the consistent definition by Fei et al. (2009), Chuaynkern et al. (2010) and Lyu et al. (2017). External measurements were made for the unnamed specimens with digital calipers (Neiko 01407A Stainless Steel 6-Inch Digital Caliper, USA) to the nearest $0.1 \mathrm{~mm}$. Mean and standard deviation (SD) were calculated in R 3.3.2 (R Core Team 2016). These measurements were as follows:

SVL snout-vent length (from tip of snout to posterior margin of vent);

HDL head length (from tip of snout to the articulation of the jaw);

HDW head width (head width at the commissure of the jaws); 
SNT snout length (from tip of snout to the anterior corner of the eye);

IND internasal distance (distance between nares);

IOD interorbital distance (minimum distance between upper eyelids);

ED eye diameter (from the anterior corner of the eye to posterior corner of the eye);

TD tympanum diameter (horizontal diameter of tympanum);

TED tympanum-eye distance (from anterior edge of tympanum to posterior corner of the eye);

HND hand length (from the proximal border of the outer palmar tubercle to the tip of digit III);

RAD radio-ulna length (from the flexed elbow to the proximal border of the outer palmar tubercle);

FTL foot length (from distal end of shank to the tip of digit IV);

TIB tibial length (from the outer surface of the flexed knee to the heel).

Sex and age were determined by secondary sexual characters, i.e., the presence of suprabrachial glands in males. Webbing formula was written according to Savage (1975).

\section{Results}

The ML and BI analyses resulted in essentially identical topologies and were integrated in Fig. 2, in which the major nodes were sufficiently supported with the Bayesian posterior probabilities $(\mathrm{BPP})>0.95$ and the bootstrap supports (BS) for maximum likelihood analysis $>70$. This mitochondrial result is consistent with the phylogenic relationship in Lyu et al. (2017). The Nidirana specimens from MDY, southern China, grouped in a clade with strong supported values and small divergences, forming a sister taxon to $N$. daunchina from western China, then together forming the sister taxon to $N$. chapaensis from northern Vietnam.

Morphologically, the specimens from MDY significantly differ from the recognized congeners by the following characteristics: (1) medium-sized body, SVL 40.4$45.9 \mathrm{~mm}$ in adult males vs. 33.3-37.1 $\mathrm{mm}$ in $N$. nankunensis; (2) finger IV longer than finger I vs. equal in $N$. chapaensis; (3) presence of lateroventral groove on every digit vs. absent on fingers and toes in $N$. pleuraden; absent or barely visible on fingers in $N$. daunchina; absent on finger I in $N$. chapaensis, $N$. lini, $N$. nankunensis, $N$. adenopleura, and $N$. okinavana; (4) tibio-tarsal articulation reaches the nostril vs. beyond the snout tip in N. lini; (5) the presence of a single nuptial pad vs. absent in $N$. hainanensis; divided into two parts in $N$. chapaensis; (6) the presence of a pair of subgular vocal sacs vs. absent in $N$. okinavana; (7) the absence of spinules on dorsal skin vs. present in $N$. adenopleura, $N$. lini and $N$. pleuraden. Detail comparison between the specimens from MDY and its congeners is listed in Table 2 with the characteristics item by item.

Further, the advertisement call from the frogs from MDY is different from the congeners by: (1) containing 1-3 fast-repeated identical regular notes (vs. containing 


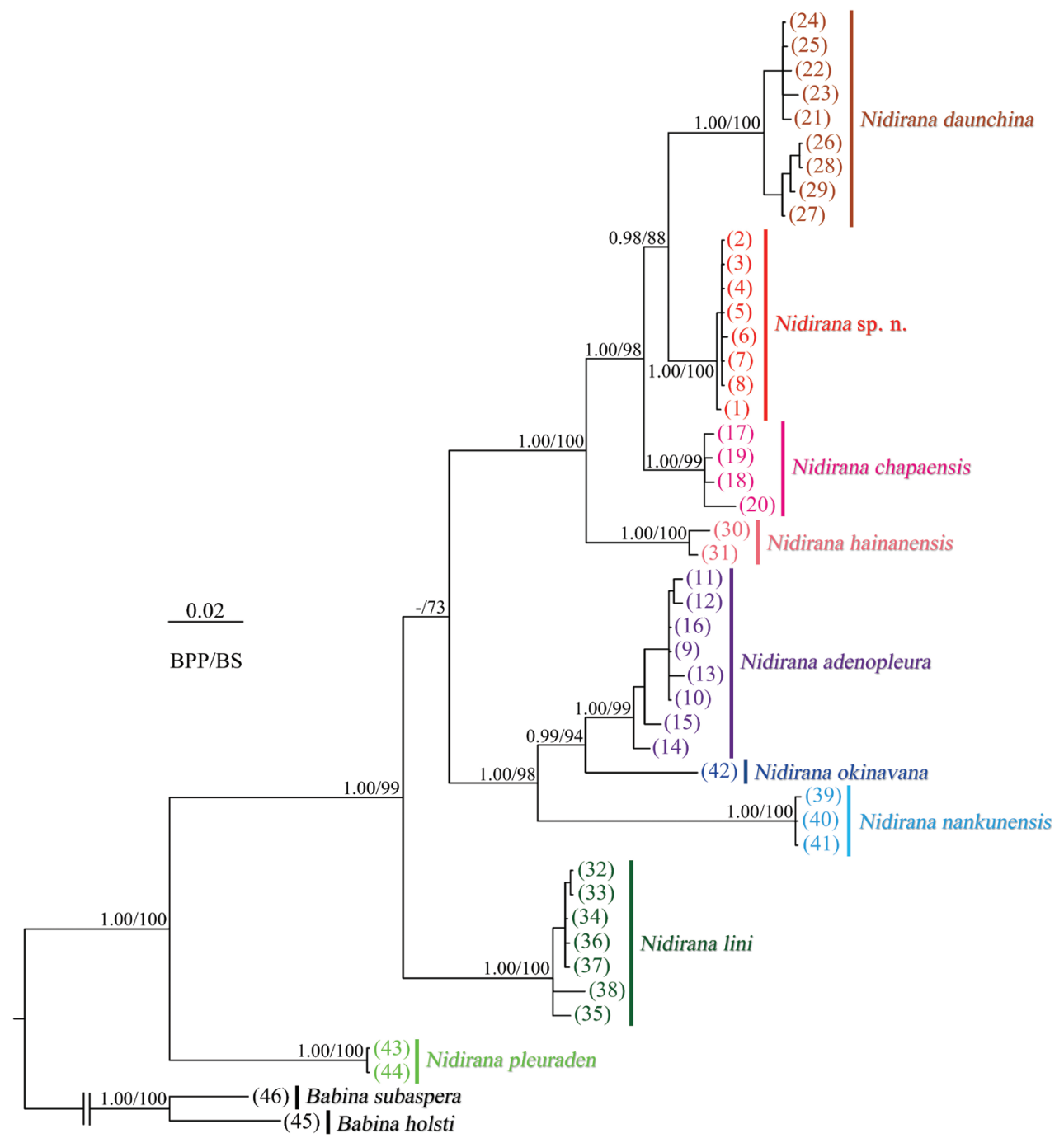

Figure 2. Bayesian inference and maximum-likelihood phylogenies. Number in parenthesis corresponds to the ID number in Table 1.

2-4 fast-repeated double-notes in $N$. hainanensis; containing a significantly different first note in $N$. daunchina and $N$. nankunensis); (2) the call notes last $30-54 \mathrm{~ms}$ vs. call notes last $115-252 \mathrm{~ms}$ in $N$. adenopleura; the first notes last $108-135 \mathrm{~ms}$ in $N$. nankunensis; the first notes last $162-197 \mathrm{~ms}$ and the others last $131-150 \mathrm{~ms}$ in $N$. daunchina; (3) the intervals between notes last $212-372 \mathrm{~ms}$ vs. last $98-213 \mathrm{~ms}$ in $N$. adenopleura; last $12-166 \mathrm{~ms}$ in $N$. nankunensis.

Therefore, based on the molecular, morphological, and bioacoustic differences, the specimens from MDY, southern China, represent an unnamed species which is described as a new species of genus Nidirana. 


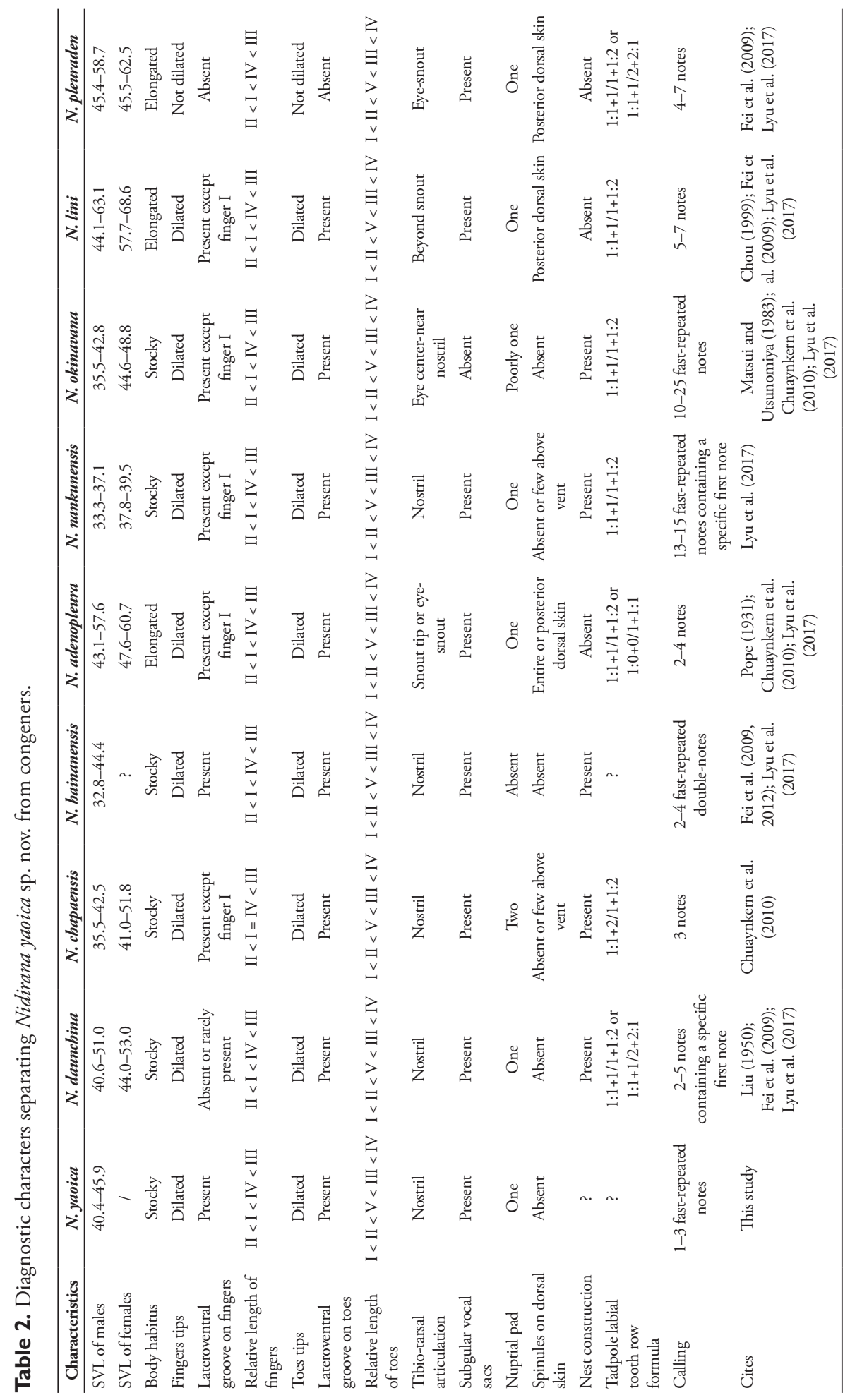




\section{Taxonomy account}

Nidirana yaoica sp. nov.

http://zoobank.org/D05423B2-1812-4AF4-890C-A0A1915BD8A6

Chresonymy. Nidirana adenopleura: Fei et al. 2009 (Mt. Dayao, Jinxiu, Guangxi); Mo et al. 2014 (Jinxiu, Guangxi)

Holotype. SYS a007022 (Fig. 3), adult male, collected by Zhi-Tong Lyu on 1 June 2018 from Mt Dayao (24.1602N, 110.2304E; ca 1190 m a.s.l.), Jinxiu Yao Autonomous County, Guangxi Zhuang Autonomous Region, China.

Paratypes. SYS a007009, 7011-7013, 7020-7021, SYS a007014/CIB 110013, seven adult males collected by Zhi-Tong Lyu, Yu-Long Li and Cheng-Yu Yang on 30 May-1 June 2018 from the same locality as the holotype. NHMG 1503043-47, five adult males collected by Yun-Ming Mo and Wei-Cai Chen on 19 March 2015 from the neighboring locality as the holotype (24.1035N,110.2294E; ca $1350 \mathrm{~m}$ a.s.1.).

Etymology. The specific name yaoica is an adjective derived from Yao, referring to the type locality of the new species, Mt Dayao in Jinxiu Yao Autonomous County, where the settlement of the Yao people is located. We suggest its English common name to be Mt Dayao music frog and its Chinese name Yao Qin Wa (瑶琴蛙).

Differential diagnosis. Nidirana yaoica sp. nov. is distinguished from its congeners by the following combination of the morphological characteristics: (1) body mediumsize and stocky, with SVL $43.8 \pm 1.7(40.4-45.9, \mathrm{n}=13) \mathrm{mm}$ in adult males; (2) disks of digits dilated, pointed; (3) lateroventral grooves present on every digit; (4) heels overlapping; (5) tibio-tarsal articulation reaching at the nostril; (6) mid-dorsal stripe present; (7) posterior of dorsal skin rough with dense tubercles but without spinules; (8) week supernumerary tubercles below the base of fingers III and IV, palmar tubercles prominent and distinct; (9) a pair of subgular vocal sacs present; (10) one single nuptial pad present on the first finger, nuptial spinules invisible; (11) suprabrachial gland large; (12) calling: 1-3 fast-repeated regular notes.

Description of holotype. Adult male. Body stocky, SVL $44.6 \mathrm{~mm}$; head longer than wide (HDW/HDL 0.92), flat above; snout rounded in dorsal and lateral views, slightly protruding beyond lower jaw, longer than horizontal diameter of eye (SNT/ ED 1.26); canthus rostralis distinct, loreal region concave; nostril round, directed laterally, closer to the snout than to the eye; a longitudinal swollen mandibular ridge extending from below nostril through lower edges, eye and tympanum to above insertion of arm, where the ridge is intermittent, forming a maxillary gland and shoulder gland; supratympanic fold absent; interorbital space flat, narrower than internasal distance (IND/IOD 1.37); pupil elliptical, horizontal; tympanum distinct, round, TD/ED 0.72 , and close to eye, TED/TD 0.38; pineal ocellus present; vomerine ridge present, bearing small teeth; tongue large, cordiform, notched behind.

Forelimbs moderately robust, lower arm 19\% of SVL and hand 27\% of SVL; fingers thin, relative finger lengths II $<$ I $<$ IV $<$ III; tip of each finger slightly dilated and remarkable elongated, forming long pointed disks; well-developed lateroventral 

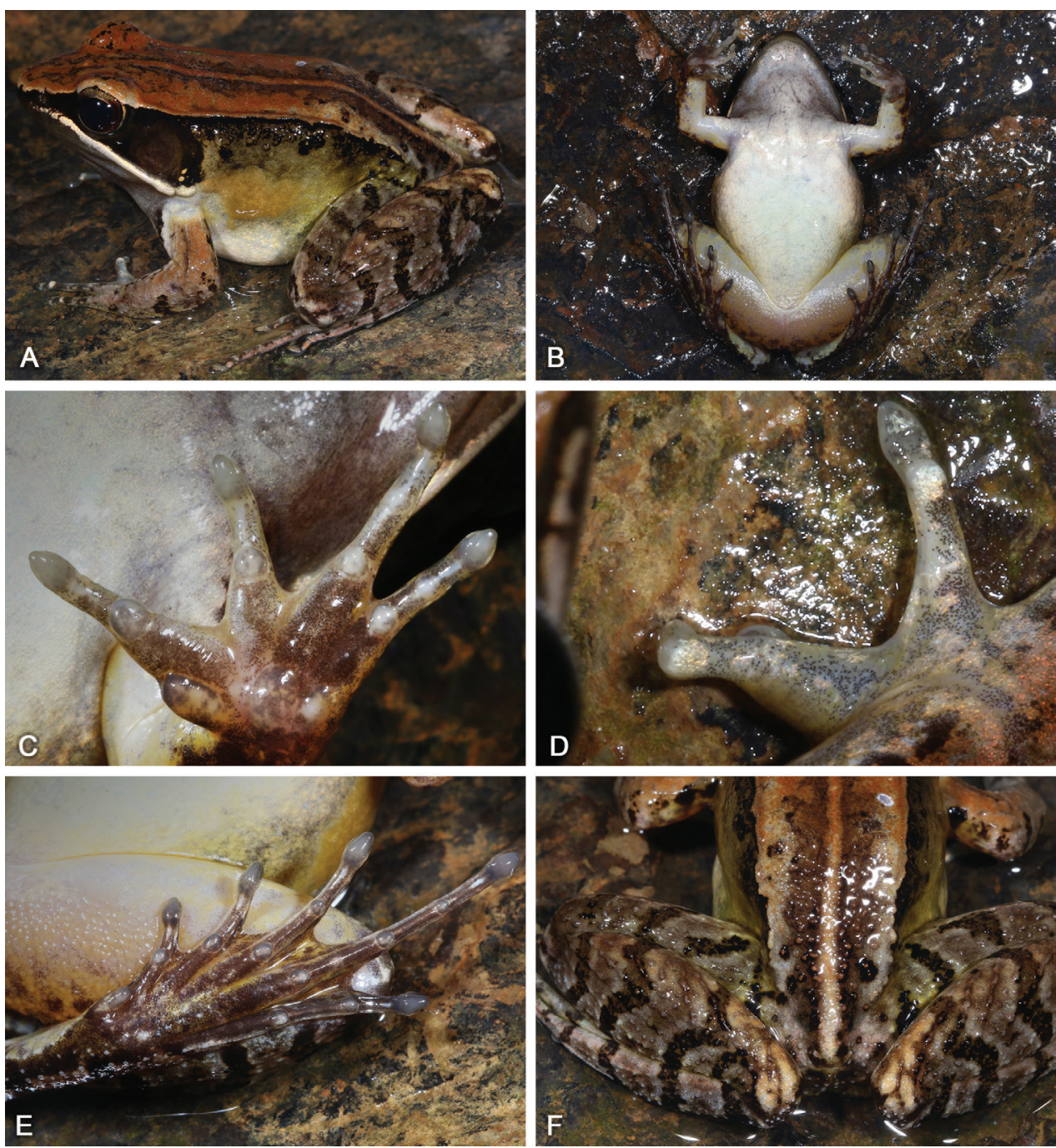

Figure 3. Morphological features of the adult male holotype SYS a007022 of Nidirana yaoica sp. nov. in life. A dorsolateral view $\mathbf{B}$ ventral view $\mathbf{C}$ left hand $\mathbf{D}$ poorly developed nuptial pad $\mathbf{E}$ left foot $\mathbf{F}$ surface of posterior dorsum and hind limbs.

grooves on all fingers, not meeting at the tip of disks; fingers free of webbing; presence of weak lateral fringes on inner and outer sides of fingers II, III and IV, and on outer side of finger I; subarticular tubercles prominent and rounded; week supernumerary tubercles below the base of fingers III and IV; three elliptic, large, prominent and very distinct palmar tubercles.

Hindlimbs relatively robust, tibia 53\% of SVL and foot $78 \%$ of SVL; heels overlapping when hindlimbs flexed at right angles to axis of body; tibio-tarsal articulation reaching the nostril when hindlimb is stretched along the side of the body; toes relatively long and thin, relative lengths I $<$ II $<$ V $<$ III $<$ IV; tip of each toe slightly 
dilated with remarkable elongated ventral callous pad, forming long and pointed disk; well-developed lateroventral grooves on toes, not meeting at the tip of disks; webbing moderate, webbing formula: I $2-2 \frac{1}{2}$ II $12 / 3-3$ III $2^{1 / 3}-3 \frac{1}{2}$ IV $31 / 2-2$ V; presence of lateral fringes on inner and outer sides of each toes, forming distinct dermal flap on the lateral edges of toes I and V; subarticular tubercles rounded, prominent; inner metatarsal tubercle elliptic, twice as long its width; outer metatarsal tubercle indistinct, small and rounded; tarsal folds and tarsal tubercle absent.

Dorsal skin of head and anterior body smooth, posterior dorsum of body rough with dense tubercles but not bearing horny spinules; developed dorsolateral fold from posterior margin of upper eyelid to above groin but intermittent posteriorly; flank relatively smooth with dense tubercles on region nearly the dorsolateral fold; a large and smooth suprabrachial gland behind base of forelimb, slightly prominent; dorsal surface of upper arm with two longitudinal ridges and slightly extending to lower arm; the dorsal surfaces of thigh and tibia with several longitudinal ridges and tubercles bearing spinules. Ventral surface of head, body, and limbs smooth; large flattened tubercles densely arranged on the rear of thigh and around vent.

Color in life of holotype. Dorsal surface of head and body reddish brown; pineal ocellus yellowish; a longitudinal reddish brown mid-dorsal stripe edged with broad dark brown, beginning from snout, across pineal ocellus, posteriorly extending to vent; several black spots on upper eyelids and posterior dorsum of body; dorsolateral fold bicolor, upper part reddish brown and lower part black; upper flank yellowish brown with irregular black spots; lower flank yellowish white; suprabrachial gland yellowish brown. Dorsal forelimbs reddish brown; a longitudinal black stripe on the anterior surface of the forelimb; irregular black marks on dorsal surface of the forelimb; dorsal hindlimbs nonuniform dark brown, four black crossbars on the thigh, three on the tibia and three on the tarsus; irregular black marks on dorsal toes. Loreal and temporal regions black, tympanum dark brown; upper $1 / 3$ iris bright brownish white and lower $2 / 3$ iris reddish brown; maxillary gland and shoulder gland yellowish white. Lips and throat grey white, but two subgular vocal sacs slightly dark colored; ventral surface of body and limbs creamy white; rear thigh tinged with pink; ventral hand and foot pale white with large black patches.

Color in preservative of holotype. Dorsal surface faded, but dark brown edges of the mid-dorsal stripe more distinct; black spots on dorsum more distinct; upper flank black; limbs faded, the crossbars clearer; ventral surface faded, throat and posterior of chest with smoky gray markings.

Variations. Measurements of type series are given in Table 3. All specimens were similar in morphology. Dorsal surface light brown in SYS a007009 (Fig. 4A), 7011, 7013 and 7020; mid-dorsal stripe begins from pineal ocellus in SYS a007011, 7013, 7014, 7020 and 7021 (Fig. 4B), unclear in SYS a007009; pineal ocellus invisible in SYS a007009.

Male secondary sexual characteristics. A pair of subgular vocal sacs, a pair of slitlike openings at posterior of jaw; a single light brown nuptial pad on the dorsal surface of first finger, nuptial spinules invisible; suprabrachial gland present.

Distribution and ecology. Currently, Nidirana yaoica sp. nov. is known only from the type locality, Mt Dayao, Jinxiu, Guangxi, in southern China. This frog inhabits in 


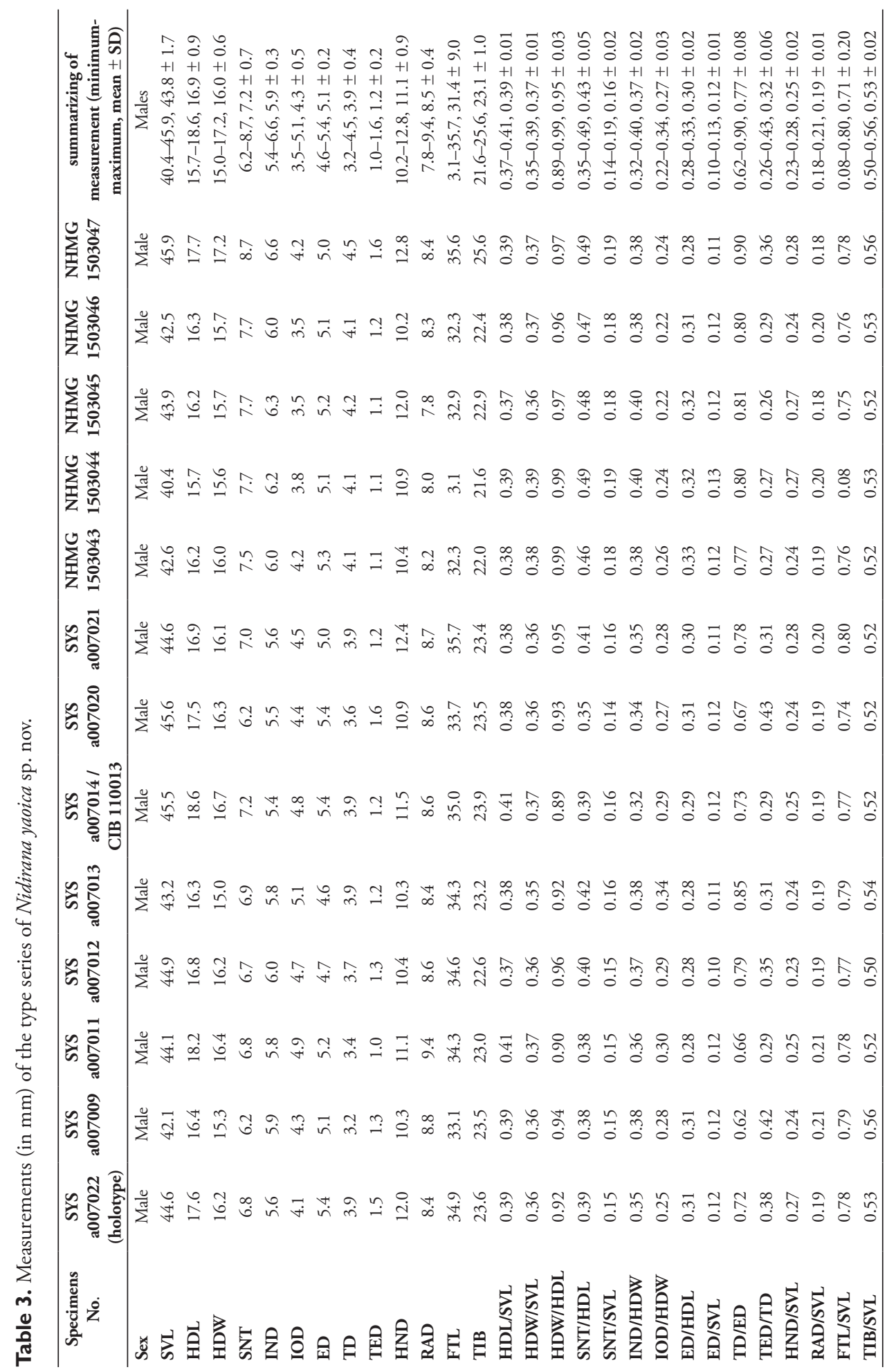



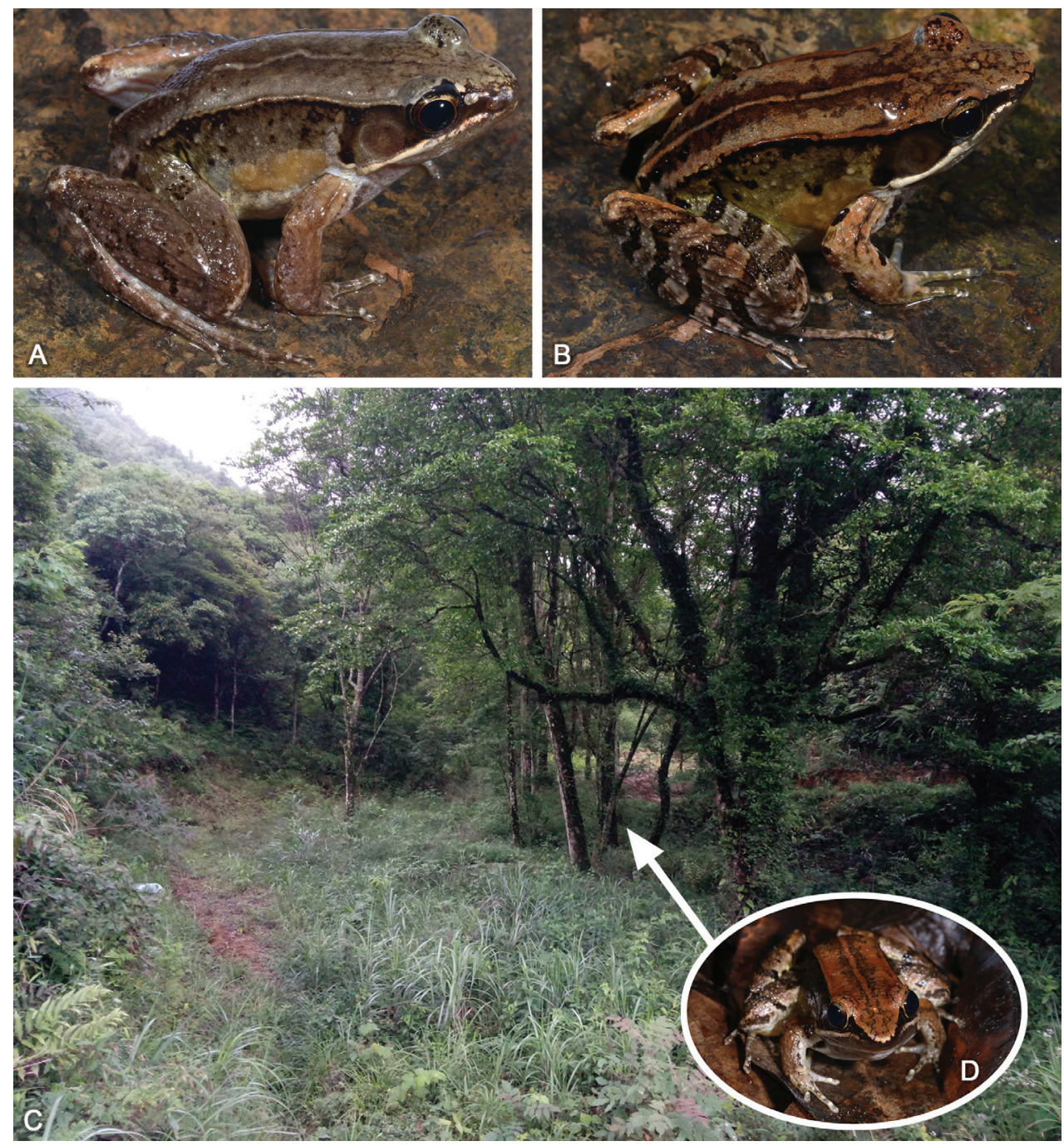

Figure 4. A, B paratypes SYS a007009 and SYS a007021 of Nidirana yaoica sp. nov. C habitat of Nidirana yaoica sp. nov. in the type locality in Mt Dayao D the holotype SYS a007022 in wild.

the swamps and ponds surrounded by moist subtropical secondary evergreen broadleaved forests (Fig. 4C, D). The adult male calls in the brushwood at the bank, from mid-March to late May. Nevertheless, the females, tadpoles, and much of the ecology and behavior of this species remain unknown.

Vocalization. The call spectrograms are shown in Fig. 5 and the measurement parameters are listed in Table 4 . The advertisement call $(\mathrm{n}=87)$ of Nidirana yaoica sp. nov. contains 1-3 rapidly repeated, identical, regular notes with the PF of $516.8 \mathrm{~Hz}$ and note IQR-BW of $172.3 \mathrm{~Hz}$ or 0 generally. The one-note call $(\mathrm{n}=25)$ has a duration of $43.3 \pm 2.7 \mathrm{~ms}$ with the rise time of $10.1 \pm 4.5 \mathrm{~ms}$. The two-note call $(\mathrm{n}=59)$ 


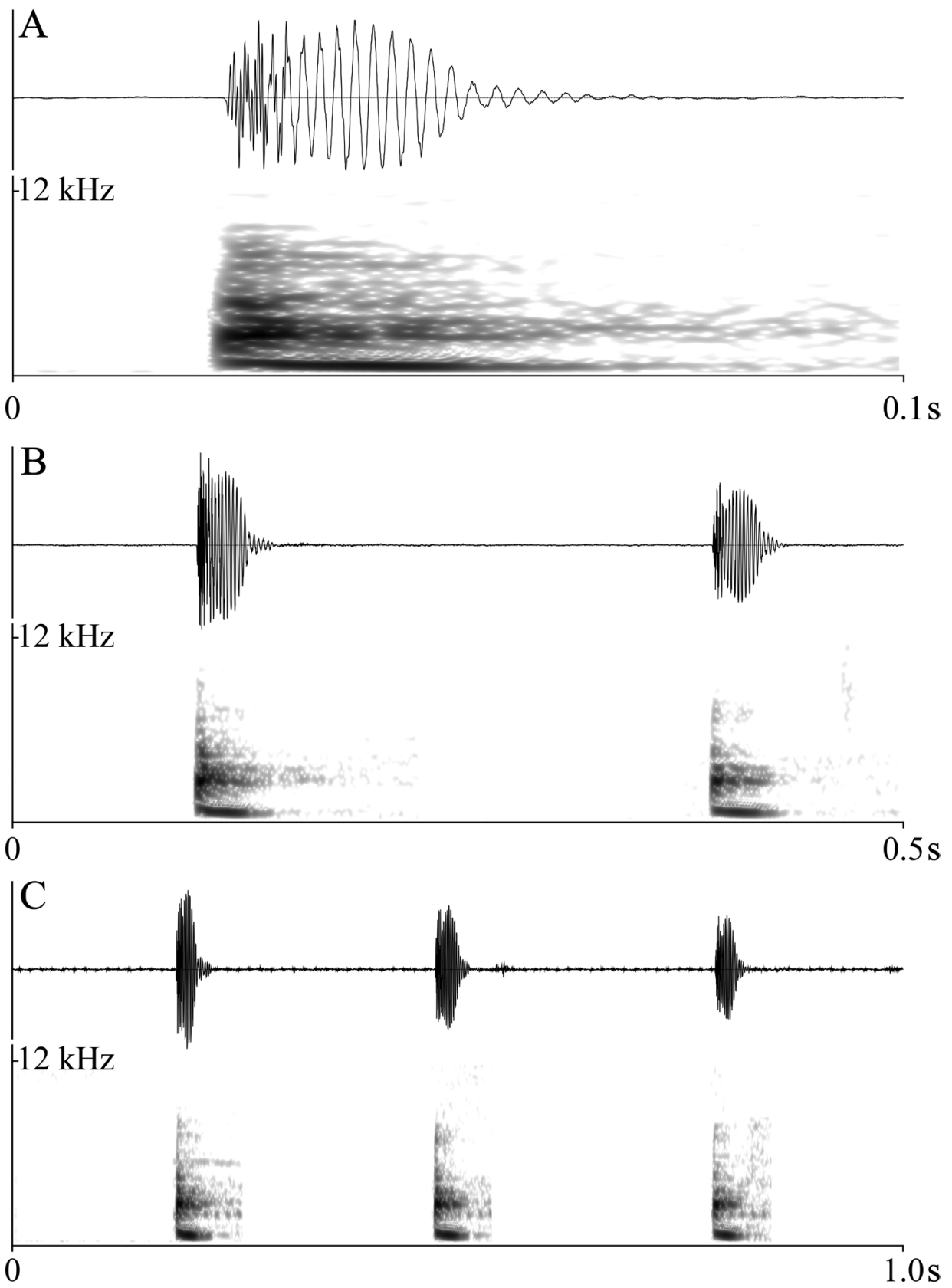

Figure 5. Advertisement call spectrograms of Nidirana yaoica sp. nov. A one-note call B two-note call; C three-note call.

has a duration of $355.9 \pm 31.1 \mathrm{~ms}$; the first note lasts $43.5 \pm 2.8 \mathrm{~ms}$ with the rise time of $8.5 \pm 4.6 \mathrm{~ms}$, and the second lasts $39.6 \pm 3.3 \mathrm{~ms}$ with the rise time of $11.6 \pm$ $4.4 \mathrm{~ms}$; the note interval last $272.8 \pm 31.7 \mathrm{~ms}$. 
Table 4. Vocalization parameters of paratype SYS a007009 of Nidirana yaoica sp. nov.

\begin{tabular}{|c|c|c|c|}
\hline & one-note call $(n=25)$ & two-note call $(n=59)$ & three-note call $(n=3)$ \\
\hline Call duration (ms) & $37-51,43.3 \pm 2.7$ & $307-454,355.9 \pm 31.1$ & $565-678,628.0 \pm 57.6$ \\
\hline Note duration (ms) & $37-51,43.3 \pm 2.7$ & $\begin{array}{l}1^{\text {st }} \text { note: } 36-51,43.5 \pm 2.8 \\
2^{\text {nd }} \text { note: } 30-49,39.6 \pm 3.3\end{array}$ & $\begin{array}{l}1^{\text {st }} \text { note: } 42-54,46.7 \pm 6.4 ; \\
2^{\text {nd }} \text { note: } 37-40,38.7 \pm 1.5 ; \\
3^{\text {rd }} \text { note: } 35-52,42.3 \pm 8.7\end{array}$ \\
\hline Note rise time (ms) & $1.6-15.5,10.1 \pm 4.5$ & $\begin{array}{c}1^{\text {st }} \text { note: } 2.0-16.0,8.5 \pm 4.6 \\
2^{\text {nd }} \text { note: } 1.7-17.9,11.6 \pm 4.4\end{array}$ & $\begin{array}{c}1^{\text {st }} \text { note: } 3.7-13.7,7.4 \pm 5.5 ; \\
2^{\text {nd }} \text { note: } 13.1-15.8,14.8 \pm 1.5 ; \\
3^{\text {rd }} \text { note: } 14.0-16.1,15.3 \pm 1.1\end{array}$ \\
\hline Note interval (ms) & l & $215-372,272.8 \pm 31.7$ & $\begin{array}{l}1^{\text {st }} \text { interval: } 212-250,234.0 \pm 19.7 ; \\
2^{\text {nd }} \text { interval: } 222-302,266.3 \pm 40.7\end{array}$ \\
\hline Call PF (Hz) & 516.8 & 516.8 & 516.8 \\
\hline \multirow[t]{2}{*}{ Note PF (Hz) } & 516.8 & $\begin{array}{c}1^{\text {st }} \text { note: } 516.8(98.3 \%) \text { or } 2584 \\
(1.7 \%) ;\end{array}$ & $1^{\text {st }}$ note: 516.8 \\
\hline & & $2^{\text {nd }}$ note: 516.8 & $\begin{array}{l}2^{\text {nd }} \text { note: } 516.8 ; \\
3^{\text {rd }} \text { note: } 516.8\end{array}$ \\
\hline \multirow[t]{3}{*}{ Note IQR-BW (Hz) } & $172.3(48.0 \%)$ or $0(52.0 \%)$ & $\begin{array}{c}1^{\text {st }} \text { note: } 344.5(8.4 \%), 172.3 \\
(45.8 \%) \text { or } 0(45.8 \%) ;\end{array}$ & $1^{\text {st }}$ note: $172.3(33.3 \%)$ or $0(66.6 \%)$; \\
\hline & & $\begin{array}{c}2^{\text {nd }} \text { note: } 172.3(54.2 \%) \text { or } 0 \\
(45.8 \%)\end{array}$ & $2^{\text {nd }}$ note: $172.3(33.3 \%)$ or $0(66.6 \%)$; \\
\hline & & & $3^{\text {rd }}$ note: $172.3(33.3 \%)$ or $0(66.6 \%)$ \\
\hline
\end{tabular}

\section{Discussion}

The taxonomic status for the Nidirana population in MDY was suspected and suggested a further study by Fei et al. (2009), despite their work reported it as $N$. adenopleura tentatively which was followed by Mo et al. (2014). Currently this population is revealed as $N$. yaoica sp. nov. in present work. In morphology, this frog is similar to $N$. hainanensis by the presence of lateroventral groove on all digits, and further to $N$. daunchina, $N$. chapaensis, and $N$. okinavana by the absence of spinules on dorsal skin. Bioacoustically, N. yaoica sp. nov. has the same calling pattern as $N$. adenopleura, which contains several fast-repeated identical regular notes, but different from the pattern in $N$. daunchina and $N$. hainanensis. The phylogenetic tree showed that the new species is closer to $N$. daunchina with moderate supports (BPP 0.98 and BS 88), and then to $N$. chapaensis and $N$. hainanensis.

The genus Nidirana was recognized as a distinct genus recently based on comprehensive evidence by Lyu et al. (2017). For the interspecific relationship within the genus, Dubois (1992) constructed two morphological species groups: $N$. pleuraden group for $N$. pleuraden and N. adenopleura group for the other known species; Fei et al. (2009) proposed $N$. daunchina group for $N$. daunchina and $N$. psaltes Kuramoto, 1985 (= N. okinavana), and $N$. adenopleura group for $N$. adenopleura, $N$. lini, and $N$. hainanensis, but excluding $N$. chapaensis, and placing $N$. pleuraden in another genus Pelophylax Fitzinger, 1843; Chuaynkern et al. (2010) suggested three species groups for Music frogs based on the morphological characters and ecological behavior of nest construction: $N$. pleuraden group for $N$. pleuraden, $N$. adenopleura group for $N$. adenopleura and $N$. lini, and $N$. okinavana group for $N$. daunchina, $N$. okinavana, and $N$. chapaensis. From the current mitochondrial results (Lyu et al. 2017; this study), the $N$. pleuraden consistently formed the 
basal lineage of this genus, while the monophyly of the three species groups $N$. adenopleura group (Fei et al. 2009; Chuaynkern et al. 2010), N. okinavana group, and $N$. daunchina group, was challenged. The main conflicts are: (1) N. okinavana was suggested morphologically more similar to $N$. daunchina and $N$. chapaensis (Fei et al. 2009; Chuaynkern et al. 2010) while clustered with $N$. adenopleura in the phylogeny; (2) N. hainanensis was suggested morphologically more similar to $N$. adenopleura and $N$. lini (Fei et al. 2009) while clustered with $N$. daunchina and $N$. chapaensis in the phylogeny; (3) $N$. lini was suggested morphologically more similar to $N$. adenopleura (Fei et al. 2009; Chuaynkern et al. 2010) while formed the basal lineage of the congeners except $N$. pleuraden in the phylogeny.

Thus we propose to follow Dubois's (1992) suggestion, regarding two species groups within the genus Nidirana: (1) N. pleuraden group, the lateroventral groove absent on fingers and toes: one species, $N$. pleuraden; (2) N. adenopleura group, the lateroventral groove present on toes, absent or present on fingers: eight species, $N$. adenopleura, $N$. okinavana, $N$. nankunensis, $N$. hainanensis, $N$. chapaensis, $N$. daunchina, $N$. yaoica sp. nov., and $N$. lini.

\section{Acknowledgements}

We thank Wei-Cai Chen, Jun Wu, and Cheng-Yu Yang for their help in the fieldwork. We are grateful to Annemarie Ohler, Yodchaiy Chuaynkern, and an anonymous reviewer for their valuable suggestions on the manuscript. This work was supported by the Project of Comprehensive Scientific Survey of Luoxiao Mountains Region of Ministry of Science and Technology, China (No. 2013FY111500), the Specimen Platform of Ministry of Science and Technology, China, teaching specimens sub-platform (No. 2005DKA21403-JK), and the Project of Animal Diversity Survey and Monitoring System Construction of Guangdong Shimentai National Nature Reserve.

\section{References}

Boersma P (2001) Praat, a system for doing phonetics by computer. Glot International 5: $341-345$.

Boettger O (1895) Neue Frösche und Schlangen von den Liukiu-Inseln. Zoologischer Anzeiger 18: 66-270.

Boulenger GA (1904) Descriptions of new frogs and snakes from Yunnan. Annals and Magazine of Natural History, Series 7: 130-135. https://doi.org/10.1080/00222930408562447

Boulenger GA (1909) Descriptions of four new frogs and a new snake discovered by Mr. H. Sauter in Formosa. Annals and Magazine of Natural History, Series 8: 492-495. https:// doi.org/10.1080/00222930908692704

Bourret R (1937) Notes herpétologiques sur l'Indochine française. XIV. Les batraciens de la collection du Laboratoire des Sciences Naturelles de l'Université. Descriptions de quinze espèces ou variétés nouvelles. Annexe au Bulletin Général de l'Instruction Publique, Hanoi. 
Chang MLY, Hsu HF (1932) Study of some amphibians from Szechuan. Contributions from the Biological Laboratory of the Science Society of China. Zoological Series 8: 137-181.

Chen L, Murphy RW, Lathrop A, Ngo A, Orlov NL, Ho CT, Somorjai IL (2005) Taxonomic chaos in Asian ranid frogs: an initial phylogenetic resolution. Herpetological Journal 15: 231-243.

Chou WH (1999) A new frog of the genus Rana (Anura: Ranidae) from China. Herpetologica 55: 389-400.

Chuaynkern Y, Ohler A, Inthara C, Duengkae P, Makchai S, Salangsingha N (2010) A revision of species in the subgenus Nidirana Dubois, 1992, with special attention to the identity of specimens allocated to Rana adenopleura Boulenger, 1909, and Rana chapaensis (Bourret, 1937) (Amphibia: Anura: Ranidae) from Thailand and Laos. Raffles Bulletin of Zoology 58: 291-310.

Dubois A (1987) Miscellanea taxinomica batrachologica (I). Alytes 5: 7-95.

Dubois A (1992) Notes sur la classification des Ranidae (Amphibiens anoures). Bulletin Mensuel de la Société Linnéenne de Lyon 61: 305-352. https://doi.org/10.3406/linly.1992.11011

Fei L, Hu SQ, Ye CY, Huang YZ (2009) Fauna Sinica. Amphibia Vol. 2 Anura. Science Press, Beijing. [In Chinese]

Fei L, Ye CY, Jiang JP (2007) A new species of Ranidae, Hylarana (Nidirana) hainanensis, from China (Amphibia: Anura). Herpetologica Sinica 11: 1-4. [In Chinese]

Fei L, Ye CY, Jiang JP (2010) Phylogenetic systematics of Ranidae. Herpetologica Sinica 12: 1-43. [In Chinese]

Fei L, Ye CY, Jiang JP (2012) Colored atlas of Chinese Amphibians and their distributions. Sichuan Publishing Group/Sichuan Publishing House of Science \& Technology, Chengdu. [In Chinese]

Frost DR (2019) Amphibian Species of the World: an Online Reference. Version 6.0. Electronic Database. American Museum of Natural History, New York, USA. http://research. amnh.org/herpetology/amphibia/index.html [accessed 7 March 2019]

Frost DR, Grant T, Faivovich J, Bain RH, Haas A, Haddad CF, de Sa RO, Channing A, Wilkinson M, Donnellan SC, Raxworthy CJ, Campbell JA, Blotto BL, Moler P, Drewes RC, Nussbaum RA, Lynch JD, Green DM, Wheeler WC (2006) The amphibian tree of life. Bulletin of the American Museum of Natural History 297: 1-291. https://doi. org/10.1206/0003-0090(2006)297[0001:TATOL]2.0.CO;2

Kuramoto M (1985) A new frog (genus Rana) from the Yaeyama Group of the Ryukyu Islands. Herpetologica 41: 150-158.

Liu CC (1950) Amphibians of western China. Fieldiana: Zoology Memoirs 2: 1-400. https:// doi.org/10.5962/bhl.title.2977

Lyu ZT, Huang LS, Wang J, Li YQ, Chen HH, Qi S, Wang YY (2019) Description of two cryptic species of the Amolops ricketti group (Anura, Ranidae) from southeastern China. ZooKeys 812: 133-156. https://doi.org/10.3897/zookeys.812.29956

Lyu ZT, Zeng ZC, Wang J, Lin CY, Liu ZY, Wang YY (2017) Resurrection of genus Nidirana (Anura: Ranidae) and synonymizing $N$. caldwelli with $N$. adenopleura, with description of a new species from China. Amphibia-Reptilia 38: 483-502. https://doi. org/10.1163/15685381-00003130

Matsui M (2007) Unmasking Rana okinavana Boettger, 1895 from the Ryukyus, Japan (Amphibia: Anura: Ranidae). Zoological Science 24: 199-204. https://doi.org/10.2108/zsj.24.199 
Matsui M, Utsunomiya T (1983) Mating call characteristics of the frogs of the subgenus Babina with reference to their relationship with Rana adenopleura. Journal of Herpetology 17: 32-37. https://doi.org/10.2307/1563777

Mo YM, Wei ZY, Chen WC (2014) Colored atlas of Guangxi amphibians. Guangxi Science\& Technology Publishing House. [In Chinese]

Pope CH (1931) Notes on amphibians from Fukien, Hainan and other parts of China. Bulletin of the American Museum of Natural History 61: 397-611.

Ronquist F, Teslenko M, Van Der Mark P, Ayres DL, Darling A, Höhna S, Larget B, Liu L, Suchard MA, Huelsenbeck JP (2012) MrBayes 3.2: efficient Bayesian phylogenetic inference and model choice across a large model space. Systematic Biology 61: 539-542. https://doi.org/10.1093/sysbio/sys029

Savage JM (1975) Systematics and distribution of the Mexican and Central American stream frogs related to Eleutherodactylus rugulosus. Copeia 2: 254-306. https://doi.org/10.2307/1442883

Schmidt KP (1925) New Chinese amphibians and reptiles. American Museum Novitates 175: 1-3.

Silvestro D, Michalak I (2012) RaxmlGUI: a graphical front-end for RAxML. Organisms Diversity and Evolution 12: 335-337. https://doi.org/10.1007/s13127-011-0056-0

Tamura K, Stecher G, Peterson D, Filipski A, Kumar S (2013) MEGA6: molecular evolutionary genetics analysis, version 6.0. Molecular Biology and Evolution 30: 2725-2729. https://doi.org/10.1093/molbev/mst197

Thompson JD, Gibson TJ, Plewniak F, Jeanmougin F, Higgins DG (1997) The CLUSTAL_X windows interface: flexible strategies for multiple sequence alignment aided by quality analysis tools. Nucleic Acids Research 25: 4876-4882. https://doi.org/10.1093/nar/25.24.4876

\section{Appendix I}

\section{Specimens examined}

Nidirana adenopleura (29): China: Fujian: Yanping District (type locality): SYS a005911-5916; Mt Wuyi: SYS a005939-5943; Jiangshi Nature Reserve: SYS a004112, 4132; Mt Yashu: SYS a005890-5891, 5901-5902; Jiangxi: Tongboshan Nature Reserve: SYS a001663-1665, 1667, 1698; Yangjifeng Nature Reserve: SYS a0000317, 0334; Jinggangshan Nature Reserve: SYS a004025-4027; Zhejiang: Jingning County: Dongkeng Town: SYS a002725-2726.

Nidirana daunchina (5): China: Sichuan: Mt Emei (type locality): SYS a0045944595; Hejiang County: Zihuai Town: SYS a004930-4932.

Nidirana hainanensis (1): China: Hainan: Mt Diaoluo (type locality): SYS a003741.

Nidirana lini (4): China: Yunnan: Jiangcheng County: Hongjiang Town (type locality): SYS a003967-3970.

Nidirana nankunensis (12): China: Guangdong: Mt Nankun (type locality): SYS a003615, 3617-3620, 4019, 4905-4907, 5717-5719 (type series).

Nidirana pleuraden (4): China: Yunnan: Mt Gaoligong: SYS a003775-3778. 